\title{
Coarticulation of consonant clusters in Italian learners of French
}

\author{
Sonia d'Apolito \\ Department of Foreign Languages, University of Salento, CRIL (Centro di Ricerche \\ Interdisciplinare sul Linguaggio), Italy.
}

https://doi.org/10.36505/ExLing-2010/03/0008/000128

\begin{abstract}
The present study focuses on how Italian learners of French as L2 coarticulate French heterosyllabic sibilant sequences and how speech rate influences the production of these non-native sequences. As in Italian consonant sequences are less frequent than in French and very rarely appear across word boundary, the hypothesis is that a different degree of coarticulation is found in clusters produced by French, as reported in the literature, and by Italian learners of French. First results appear to confirm our expectations. A small degree of coarticulation characterises clusters produced by Italian, especially in comparison to what has been observed for French natives even if at a fast speech rate some cases of place assimilation are observed.
\end{abstract}

Key words: place assimilation, speech rate, L2.

\section{Introduction}

Since in Italian language consonant sequences across word boundary appear in case of prepositions or loanwords Farnetani, Busà, (2004); Muliačić, (1973), it is interesting to observe which degree of coarticulation Italian learners can realize when they pronounce non-native sequences. Sibilant clusters are studied along the lines of a recent study on place assimilation in French by Niebuhr et al. (2008). In their study, the authors investigated sequences of alveolar and postalveolar sibilants produced across word boundary at a natural speech rate finding evidence for the presence of place assimilation, although French was claimed not to have it (Walker, 1982).

The study presented here investigates the same sibilant clusters in French productions of Italian learners analysing both acoustic and kinematic data. Moreover, it takes into account speech rate as an important factor since it facilitates coarticulation as a result of an increasing coproduction between successive segments (Byrd, 1996). The hypothesis is that Italian learners' production is characterised by a small degree of coarticulation because of mother tongue's influence. As described in literature Davidson (2006) and Oh (2008), a transitional schwa will be inserted within the clusters keeping them away, even if at a faster speech rate a stronger coarticulation between segments is expected. However, it seems quite improbable the realization of place assimilation by Italian learners of French.

ExLing 2010: Proceedings of 3rd Tutorial and Research Workshop on Experimental Linguistics, 25-27 August, Athens, Greece 


\section{Method}

Target heterosyllabic sibilant clusters, /sB/, /Bs/, /sC/, /Cs/, /zB/, /zB/, were studied in a /a_i/ surrounding vowel context, proposed within a carrier phrase. In this study two main factors were considered: prosodic boundary and speech rate. As a prosodic boundary could interfere with the coarticulatory process, stimuli were inserted within a phonological phrase (with no boundary; e.g. "Il a dit sage syrien rapidement" He said Syrian wise person quickly), and an intonational phrase boundary (with a prosodic boundary; e.g. "D'abord il a dit sage, syrien l'a dit après" Before he said Syrian, wise person has been said after). In order to facilitate the coarticulation of clusters, subjects (two Italian learners of French, SPK1 and SPK2) repeated the corpus seven times, both at a normal and at a faster speech rate.

Acoustic and kinematic (EMMA, Ultrasound) data were collected simultaneously at CRIL laboratory. Here only acoustic data will be discussed. Auditory analysis and acoustic labelling were performed in PRAAT while MATLAB and PRAAT scripts were used for measurements. The auditory analysis aimed at verify cluster and boundary realization. The labelling were related to: 1) segment boundaries of the $\mathrm{V}_{1} \mathrm{C}_{1} \# \mathrm{C}_{2} \mathrm{~V}_{2}$ sequence, including final schwa and/or pause; 2) three points at the vowel steady-state $(30 \mathrm{~ms})$ and a point at the vowel transition in $\mathrm{V}_{1}, \mathrm{~V}_{2}$ and in the schwa, if present. Acoustic measurements carried out were: duration of all segments; for each vowel, values of first three formants; for each sibilant, mean value and range of the Centre of Gravity $(\mathrm{CoG})$ in $\mathrm{Hz}$, for frequencies between $1.5-15 \mathrm{kHz}$. The acoustic analysis presented below focuses on the latter measurement. Indeed, the $\mathrm{CoG}$ represents the average value of the frequencies in the spectrum weighted by the amplitude Gordon et al. (2002). CoG gives good information about the place of articulation of fricatives and it will be useful for distinguishing alveolars from palatals both from an acoustic and perceptive point of view.

\section{Results}

Acoustic analysis reveals that, as described in literature, both speakers inserted a transitional schwa between the two segments at both speech rates. Thus the two sibilant on average are kept away even if SPK1 when talking faster realizes a schwa in few cases. Results of CoG values carried on the first/second cluster position are displayed in Figure 1. Two regions are visible in the plot, corresponding to palatals- with low mean CoG values, range between 5 and $6.5 \mathrm{kHz}$ - and alveolars- with higher mean CoG values, range between 6.8 and $9 \mathrm{kHz}$. Univariate ANOVA shows that the mean $\mathrm{CoG}$ value (dependent variable) is significantly different depending on the type of sibilant (independent variable) $([\mathrm{F}(5,606)=2,711 \mathrm{p}=, 020])$. 


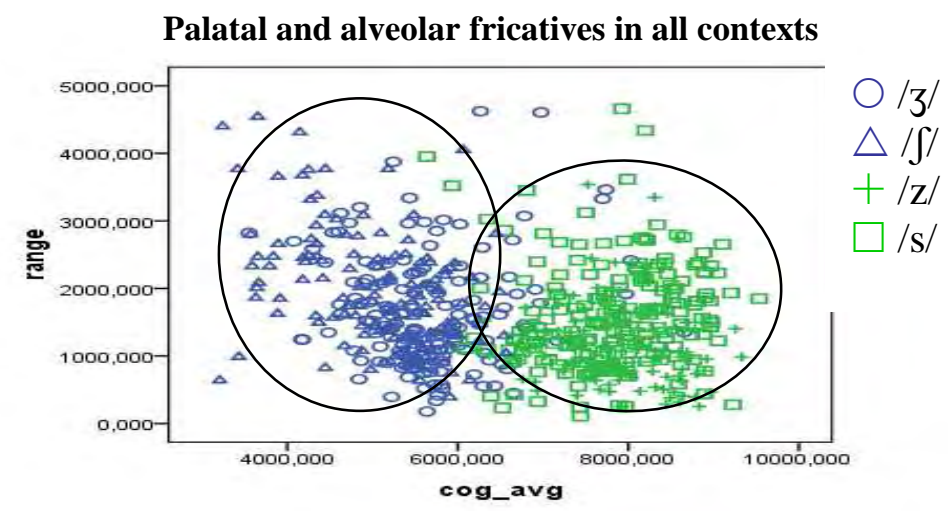

Figure 1: Scatterplot of mean $\mathrm{CoG}$ values for each sibilant within all contexts. On y-axis is represented $\mathrm{CoG}$ range while on $\mathrm{x}$-axis the mean CoG. Blue indicates palatals (left circle); Green indicates alveolars (right circle).

Individual univariate ANOVAs and post-hoc tests (Tukey) with sibilant type as independent variable and mean $\mathrm{CoG}$ as the dependent were carried on each consonant position, prosodic boundary and speech rate. At normal speech rate, schwa insertion took place. In this case the type of consonant, in both positions, plays a significant role in affecting the mean CoG values. Values for the two speakers in both no-boundary and boundary conditions shows that: no boundary: $\mathrm{C}_{1}: \mathrm{F}(5,42)=22,93 \mathrm{p}=, 000$ for SPK1; $\mathrm{F}(5,41)=64,544, \mathrm{p}=, 000$ for SPK2; $\mathrm{C}_{2}:(\mathrm{F}(5,34)=50,84 \mathrm{p}=, 000$ for SPK1; $\mathrm{F}(5,40)=22,69 \mathrm{p}=, 000$ for SPK2; boundary conditions: $\mathrm{C} 1: \mathrm{F}(5,41)=32,96$ $\mathrm{p}=, 000$ for SPK1; $\mathrm{F}(5,40)=112.48 \mathrm{p}=, 000$ for SPK2; C2: $\mathrm{F}(5,39)=78,98$ $\mathrm{p}=, 000$ for SPK1; $\mathrm{F}(5,40)=39,49 \mathrm{p}=, 000$ for SPK2). Post-hoc tests show that mean CoG values of palatals are lower than those of alveolars meaning that alveolar and palatal fricatives are kept away at normal speech rate.

At faster speech rate, schwa insertion did not take place with the exception of some cases. In this case the type of consonant plays again a significant role in affecting CoG values for both speakers in both noboundary and boundary conditions: no-boundary: $\mathrm{C} 1: \mathrm{F}(5,24)=4,78 \mathrm{p}=, 006$ for SPK1; $F(5.38)=16,83 \mathrm{p}=, 000$ for SPK2; 2 : $F(5,40)=4,13 \mathrm{p}=, 005$ for SPK1; $\mathrm{F}(5,37)=30,43 \mathrm{p}=, 000$ for $\mathrm{SPK} 2$; boundary conditions: $\mathrm{C} 1$ : $\mathrm{F}(5,28)=19,51$ for SPK1; $\mathrm{F}(5,33)=106,03$ for SPK2; C2: $\mathrm{F}(5,28)=10,15$ $\mathrm{p}=, 000$ for SPK1; $\mathrm{F}(5,34)=35,32 \mathrm{p}=, 000$. Results of post-hoc tests show that mean CoG values of palatals are lower than those of alveolars, regardless of position fricatives appeared. Thus, the two speakers keep away the two segments.

Apart from the case of /Cs/ and /Bs/ clusters for SPK1's production in which COG values show that some cases of place assimilation are realized. 
This observation was consistent with the author's auditory analysis. Univariate ANOVA performed on these clusters shows that the type of consonant is non significant in affecting $\mathrm{C} 2$ 's $\mathrm{CoG}$ values $[\mathrm{F}(2,61)=, 680$ $\mathrm{p}=0.51]$. This means that $\mathrm{CoG}$ values of alveolars is not significantly different from the mean value of palatals. Moreover, as the CoG mean values range between 5.7 and $6.8 \mathrm{kHz}$, data also show that the alveolar fricatives were palatalized. However, t-test results on speed rate (total duration of phrase/number of syllables realized ratio) shows that productions of both speakers are significantly different depending on the speech rate (with speed rate values significantly for both speakers SPK1 and SPK2 $\mathrm{p}=, 000$ ). Nevertheless the t-test also shows that SPK1's productions are always significantly faster than SPK2's productions $t=4,878 \mathrm{p}=, 000$ for normal and $t=7,369 p=, 000$ for fast rate). The faster rate may of course have favoured the assimilatory process.

\section{Conclusion}

Italian learners' production of French sibilant clusters seems to be affected by mother tongue phonetics and phonology. The two speakers analysed so far realized cluster at normal rate with intervening schwas, both within and across prosodic constituents. On the other hand fewer schwa insertions is observed in the case of faster rate, independently of prosodic position. Preliminary acoustic (centre of gravity) results show that alveolar and palatal fricatives are kept distinct. However, at fast speech rate, some cases of place progressive assimilation are realized by one speaker, with alveolar fricatives showing a mean $\mathrm{CoG}$ value similar to preceding palatal fricatives.

\section{References}

Byrd, D., Tan, C.C. 1996. Saying consonant clusters quickly. Journal of Phonetics 4, 263-282.

Davidson, L. 2006. Phonology, phonetics or frequency: influences on the production of non-native sequences. Journal of Phonetics 34, 104-137.

Farnetani, E., Busà, M.G. 2004. Italian clusters in continuous speech. Proc. of the $3^{\text {rd }}$ ICSLP, vol. 1, 359-362, Yokohama, Japan.

Gordon M., Barthmaier P., Sands K. 2002. A cross-linguistic study of voiceless fricatives. JIPA vol. 32, 133-139.

Muliačić, Z. 1973. Fonologia della lingua italiana. Ed. Il Mulino, Bologna.

Niebuhr O., and al.. 2008. On place assimilation in French sibilant sequences. Proc. of the VII ISSP, 221-224, Strasbourg, France.

Oh, E., 2008. Coarticulation in non-native speakers of English and French: an acoustic study. Journal of phonetics 36, 361-384.

Walker, D.C. 1982. On a phonological innovation in French. Ed. Cambridge University Press, vol. 12, 72-77. 